\section{Atypical presentation of thymolipoma}

\section{Canan Kucuk, ${ }^{1}$ Kemal Arda, ${ }^{2}$ Naim Ata, ${ }^{3}$ Mustafa Hamidullah Turkkani ${ }^{4}$}

'Department of Anesthesiology and Reanimation, 29 Mayıs Hospital, Ankara; 2Department of Radiology, Atatürk Research and Education Hospital, Ankara; ${ }^{3}$ Department of Internal Medicine, 29 Mayıs Hospital, Ankara; ${ }^{4}$ Department of Chest Disease, 29 Mayıs Hospital, Ankara, Turkey

\section{Abstract}

Thymolipoma is an uncommon benign neoplasm and its pathogenesis is unclear. The current study describes the case of an 82-year-old woman who presented with dyspnea and dysphagia and was discovered to have an anterior mediastinal thymolipoma enlarged to cranial part of the neck. We conclude that the only curative treatment of thymolipomas is surgical excision.

\section{Introduction}

Thymolipoma is an uncommon benign neoplasm which accounts for 2 to $9 \%$ of thymic tumors. ${ }^{1}$ There is no sex difference in its incidence, and the onset can occur at any age. ${ }^{2}$ Thymolipomas usually grow slowly and can reach large sizes before the diagnosis. Images on Xrays may mimic cardiomegaly. ${ }^{3}$ When the patient experiences symptoms, they are usually related to compression of adjacent structures, such as the heart, the great vessels, the lungs or the bronchi. ${ }^{4}$ This benign neoplasm can be associated with some autoimmune disorders, such as myasthenia gravis, systemic lupus erythematosus, hypogammaglobulinemia, Graves' disease and red cell aplasia. ${ }^{5}$ The pathogenesis of thymolipoma is unclear and has been the subject of much speculation. On a computed tomography (CT) scan, the tumor appears almost entirely fatty with some areas of inhomogeneity of softtissue density, which represent thymic tissue. ${ }^{6}$ Its sharp borders, its lack of compression of nearby vessels, and its location point to a benign lesion. Herein, we report a 82-year-old female case who presented with dyspnea and dysphagia and was diagnosed with an anterior mediastinal thymolipoma enlarged to the cranial part of the neck.

\section{Case Report}

An 82-year-old woman was admitted with complaints of mild dyspnea and dysphagia for about one week. Her medical history revealed arterial hypertension and thyroidectomy 20 years ago. On physical examination there were no remarkable findings. Her blood pressure was $140 / 100 \mathrm{mmHg}$ and heart rate was 100 bpm. Her pulses were palpable, symmetric and rhythmic, with no changes in the peripheral perfusion. On pulmonary auscultation, the respiratory sounds were present bilaterally, and no rales were heard. The biochemical tests and electrocardiogram showed no specific changes. On chest radiography, a mild enlargement of the cardiac area was observed. The CT revealed the presence of an expanding lesion with a fat attenuation coefficient $[-89.1 \pm 28.4$ Hounsfield unit (HU)], regular and precise contours, located in the anterior mediastinum. The lesion was measured $7.4 \times 6.6 \times 9.5 \mathrm{~cm}$ (WxLxH) and was suggestive of thymolipoma (Figures 1-2). The patient was referred for surgical treatment. However, she did not give a consent for surgery.

\section{Discussion}

Lange, in 1916 first described a case with thymolipoma. ${ }^{7}$ Thymolipomas are rare, slowgrowing mediastinal tumors which are usually present as asymptomatic tumors. ${ }^{7}$ Most are discovered incidentally. They are asymptomatic until marked mass effect occurs. Grossly, thymolipomas are yellow, have a soft consistency and a bilobular configuration, and wellencapsulated which makes them very similar to the normal thymic gland. ${ }^{8,9}$ They are usually large and may progress to huge masses. In $68 \%$ of the cases, these tumors weighed more than $500 \mathrm{~g}$, while in $23 \%$ of the cases, they exceeded $2000 \mathrm{~g}^{6,9}$ The largest tumor described weighed

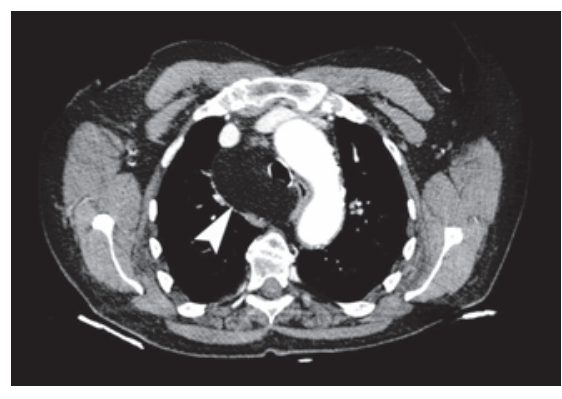

Figure 1. The computed tomography showed the tumor (arrow) with a fat attenuation coefficient $(-89.1 \pm 28$.4 Hounsfield unit), regular and precise contours, located in the mediastinum.
Correspondence: Canan Kucuk, 29 Mayıs Hospital, Anestezi Böl. 06105, Ankara, Turkey. Tel: +90.532.7142484 - Fax: +90.312.5932935.

E-mail: canankuc@yahoo.com

Key words: Thymolipoma; Benign neoplasm; Dyspnea; Dysphagia.

Received for publication: 16 November 2015

Revision received: 14 March 2016.

Accepted for publication: 18 March 2016.

This work is licensed under a Creative Commons Attribution NonCommercial 4.0 License (CC BYNC 4.0).

(C) Copyright C. Kucuk et al., 2016

Licensee PAGEPress, Italy

Chest Disease Reports 2016; 4:5634

doi:10.4081/cdr.2016.5634

more than 12,000 g. ${ }^{8,9}$ Diaphragmatic hernias are commonly considered in the differential diagnosis of fat-containing mediastinal masses. ${ }^{10}$ These are Morgagni and Bochdalek hernias containing fatty tissue; however, most of them are found in the lower mediastinum. Lipomas which have different ratios of fibrous septa are seen second frequently. ${ }^{11}$ Lipomatosis are fat-density masses which spread cardiophrenic and paraspinal fields, and mostly tracheal compression is seen. Also, lipomatosis may result from Cushing syndrome, steroid therapy, obesity and diabetes as a result. ${ }^{10,12}$ Diagnosis of intrapericardial and epicardial adipose tissue is simply and found as fat masses in the paracardiac area. ${ }^{13}$ Rare masses such as angiomyolipomas, liposarcomas, teratomas, and thymolipomas should be considered in the differential diagnosis of mediastinal masses containing fat. ${ }^{14}$ Angiomyolipomas show vascular structures in CT examination, whereas liposarcomas show mostly soft tissue density and inhomogeneous

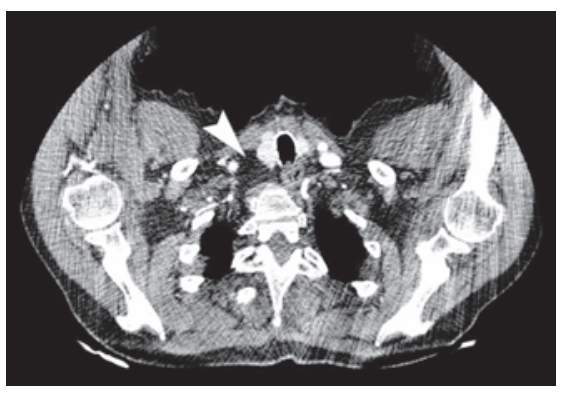

Figure 2. On computed tomography examination, thymolipoma extending to cranial part of the neck was seen (arrow). 
internal parenchyma with soft tissue and fatty component. $^{10}$

In addition, teratomas show homogeneous soft tissue density with curvilinear peripheral or central calcification, rim or septal enhancement can be seen. ${ }^{15}$

In our case, a homogeneous mass of fat density localized in the upper right anterior without invading the surrounding structure. The differential diagnosis can be easily made based on the homogeneous nature without internal septa and vascular streak, showing homogeneous enhancement. However, large thymolipoma lesions droop inferiorly from the anterior mediastinum toward diaphragm. In this case, the mass was extending to the cranial part of the neck, showing an unusual pattern.

\section{Conclusions}

The definitive diagnosis is based on the histopathological findings. Fine needle aspiration biopsy is not always helpful to differentiate between a thymolipoma and other fatty mediastinal lesions, such as well-differentiated liposarcomas. ${ }^{16}$ This case shows an atypical presentation of a thymolipoma, a rare, benign thymic tumor which can occasionally result in respiratory symptoms without reaching large sizes. The only curative treatment of thymolipomas is surgical excision.

\section{References}

1. Halkos ME, Symbas JD, Symbas PN. Acute respiratory distress caused by massivethymolipoma. South Med J 2004;97:1123-5.

2. Moran CA, Rosado-de-Christenson M, Suster S. Thymolipoma: clinicopathologic review of 33 cases. Mod Pathol 1995;8:7414.

3. Gamanagatti S, Sharma R, Hatimota P, Guleria R, Arvind S. Giant thymolipoma. Am J Roentgenol 2005;185:283-4.

4. Ceran S, Tulek B, Sunam G, Suerdem M. Respiratory failure caused by giant thymolipoma. Ann Thorac Surg 2008;86:661-3.

5. Wang Y, Sun Y, Zhang J, et al. Diagnosis, treatment and prognosis of thymoma: an analysis of 116 cases. Chin Med J 2003;116:1187-90.

6. Yeh HC, Gordon A, Kirschner PA, Cohen BA. Computed tomography and sonography of thymolipoma. Am J Roentgenol 1983;140:1131-3.

7. Lange L. Überein lipom des thymus. Zentralbl Allg Pathol 1916;27:97.

8. Barnes RDS, 0'Gorman P. Two cases of aplastic anaemia associated with tumours of the thymus. J Clin Pathol 1962;15:264.

9. Teplick JG, Nedwich A, Haskin ME. Roentgenographic features of thymolipoma. Am J Roentgenol 1973;117:873.

10. Romero Guadarrama MB, Durán Padilla
MA, Cruz Ortiz H, et al. Diagnosis of thymolipoma with fine needle aspiration biopsy. Report of a case initially misdiagnosed as liposarcoma. Acta Cytol 2004;48:441-6.

11. Tateishi U, Gladish GW, Kusumoto M, et al. Chest wall tumors: radiologic findings and pathologic correlation: part 1. Benign tumors. Radiographics 2003;23:1477-90.

12. Meng K, Lee $\mathrm{CH}$, Saremi F. Metabolic syndrome and ectopic fat deposition: what can CT and MR provide? Acad Radiol 2010; 17:1302-12.

13. Petris A0, Alexandrescu DM, Costache II. Cardiac tumors. Rev Med Chir 2014;118:289-92.

14. Rubush JL, Gardner IR, Boyd WC, Ehrenhaft JL. Mediastinal tumors. Review of 186 cases. J Thorac Cardiov Sur 1973;65:216-22.

15. Juanpere S, Canete N, Ortuno P, et al. A diagnostic approach to the mediastinal masses. Insights Imaging 2013;4:29-52.

16. Romero Guadarrama MB, Duran Padilla MA, Cruz Ortiz H, et al. Diagnosis of thymolipoma with fine needle aspiration biopsy. Report of a case initially misdiagnosed as liposarcoma. Acta Cytol 2004;48: 441-6. 